\title{
The treatment of chronic pain with psychotropic drugs
}

\author{
H. MerSKeY \\ D.M., M.R.C.Psych., D.P.M.
}

R. A. Hester*

M.B., B.S., D.P.M.

\section{The National Hospitals for Nervous Diseases, Queen Square and Maida Vale, London}

\begin{abstract}
Summary
The treatment is described of thirty patients with chronic nervous system lesions causing intractable pain. Moderately good relief of pain was obtained with a combination of phenothiazines (especially pericyazine), antidepressant drugs and antihistamines.

The theoretical implications of this are discussed and it is suggested that the drugs in question act partly by virtue of an effect on the multisynaptic neuronal systems whose activities are related to the experience of pain.
\end{abstract}

A WIDE range of psychological circumstances will cause, exacerbate or relieve pain. Anxiety frequently produces pain or makes it worse, whilst the reduction of anxiety by drugs, psychotherapy and plain suggestion may alleviate pain. The evidence for this view-which is generally agreed-has been reviewed elsewhere (Merskey \& Spear, 1967).

Anaesthetists are very active in studying the techniques of discussion and support which will relieve postoperative pain. For example Egbert et al. (1964) showed that in patients who were given suitable preoperative encouragement smaller doses of analgesic drugs were required postoperatively than by a control group. It is worth noting however, that, as a rule, pain tends to be reduced rather than abolished by psychological techniques. The complete removal of severe pain often requires potent drugs.

Although many analgesics are known there is sometimes a mistaken impression that, if paracetamol and pentazocine fail, the patient with chronic pain due to an organic lesion faces the alternatives of depending on more or less dangerous drugs or undergoing a neurosurgical operation with sometimes considerable risks. It is of course well recognized that certain pain-syndromes, especially headache and facial pain may yield to antidepressant medication. Lascelles (1966) showed this in a controlled trial. There is an impression, however, that those patients improve who show depression-and perhaps it was the depression that produced the pain. Certainly one of us (Merskey, 1965) found that antidepressants only helped psychiatric patients with pain where there was an affective illness which could ordinarily be expected to respond to the treatment

\footnotetext{
* Present address: Netherne Hospital, Coulsdon, Surrey.
}

of depression, and phenothiazines were of little help for pain which was mainly due to psychological illness. On the other hand, Lance \& Curran (1964) recorded the view that amitriptyline could have an analgesic effect which was independent of its antidepressant action, although this claim was criticized severely by Holt (1964) on statistical grounds.

A number of reports indicate that phenothiazines can play a part in the control of pain which has a definite organic basis. Sigwald, Hebert \& Quetin (1957) described the successful treatment of resistant forms of pain with promethazine which is both a phenothiazine and an antihistamine. They obtained still better results with chlorpromazine. Sigwald, Boutier \& Caille (1959) reported yet more effect from levomepromazine. Lasagna \& De Kornfeld (1961) showed that methotrimeprazine was as effeco tive as morphine when given for postoperative pain Other reports recording the use of phenothiazines for chronic pain were provided by Panaccio (1959); Chavanne (1960) and Paradis (1962). Montilla, Frederik \& Cass (1963) also demonstrated analgesic effects of phenothiazines. Diphenhydramine hydrochloride, an antihistamine has been reported to markedly potentiate the effects of novocaine (Rosner, 1957). Doctors engaged in the treatment of pain from neoplasms also recognize an analgesic effect of tranquillizers, although they tend to attribute it wholly or mainly to the abating of fear (Saunders, 1963; Bloomfield et al., 1964; Saunders \& Winner, 1971).

Even with chronic pain from non-progressive lesions, for instance in the thalamic syndrome, there is evidence that phenothiazines may be strikingly beneficial, without the patient having shown notable evidence of anxiety (cf. for example, the report by Lassmann, Moody \& Gryspeerdt, 1959).

These reports indicate that a fairly sustained use of psychotropic drugs like tricyclic antidepressants and phenothiazines, with, perhaps, antihistamines, could be helpful in the management of chronic pain. It is an open question as to whether their effect takes place solely because anxiety is reduced or partly because they have some additional analgesic qualities. Since other powerful anxiolytic agents like chlordiazepoxide are not usually effective for severe chronic pain it is reasonable to suppose that the analgesia is not only due to the reduction of anxiety. 
One of us (H.M.) sees numerous patients who are referred for treatment of pain, whether or not this is attributable to psychological causes. Many, in fact, have pain due primarily to organic lesions, almost all of which affect the nervous system and are not progressive. In treating this latter group we have come to rely quite heavily on various sorts of nonnarcotic medication. We think it may be useful to others to describe the practice employed and some of its results. The treatment situation is such that controls or systematic study of the effects of each drug alone is not feasible. Yet our methods appear to be helpful to people for whom surgery may be the only alternative. We therefore offer an account of thirty patients with whom we have used mixtures of psychotropic drugs, and their response to this medication.

\section{Patients and treatments}

The patients concerned are eleven men and nineteen women selected for the presence of severe persistent pain related to an organic lesion. Their median ages are-males, 58 years; females, 56 years. Seven patients were single or widowed. The median duration of illness was 5 years for men and 4 years for women, with an overall range of from 6 months to 25 years of pain. The diagnoses were: postherpetic neuralgia (seven patients), thalamic syndrome (six patients), facial pain (six women and one man), causalgia (five patients), phantom pain (one patient), Paget's disease of the leg bones (one patient), cervical spondylosis (one patient), and carcinoma (two patients).

Nine patients had undergone operative procedures for their pain, sometimes repeatedly and seven more were receiving narcotic analgesics (including the two patients with neoplasms). Two patients had had ECT and seven had had antidepressants. Five of the latter seven had also had phenothiazines, as had one other patient. Carbamazepine had also been tried in six cases. Many patients had lost count of their drug treatments and analgesic tablets taken so that the above represent minimum estimates.

Neurological data for these patients were readily available, often with useful information on the patient's social circumstances and mood. The approach used was then to complete a psychiatric history, explaining that one of us (H.M.) was particularly interested in the treatment of pain and also in any personal problems or circumstances which might make the pain harder to tolerate. All but one of the thirty patients showed evidence of moderate depression. In all but one of the twentynine with depression it was thought that the depression was secondary to the pain rather than primary. The exception was a woman with manic-depressive mood-swings and post-herpetic neuralgia who had few complaints when elated. In at least two of the patients with a thalamic syndrome it was hard to be sure, however, whether the depression and pain did not originate simultaneously from the brain damage and one in fact responded well to ECT, being the only one to whom it was given.

Treatment was inevitably complex. Some patients had physiotherapy (e.g. for cervical spondylosis) and the use of a vibrator, and drugs of the following types were used in varying combinations:

(1) Narcotic analgesics in four of the seven who had originally received them, albeit in reduced doses in two instances.

(2) Non-narcotic analgesics, especially pentazocine, paracetamol and dextropropoxyphene and the proprietary combination of the latter two (Distalgesic).

(3) Antidepressants.

(4) Phenothiazines.

(5) Antihistamines, especially promethazine.

\section{Results}

The median period of follow-up was 6 months. Using two or more of the possible combinations of these drugs substantial relief was provided for twelve patients, moderate relief for nine and slight relief for seven. No improvement occurred in two.

Ideally it would have been desirable to have used each type of drug separately so as to evaluate the effects in comparison with other types. The attempt was made, in part, to do this, but with limited success, since it is hard and probably wrong to postpone the use of potentially effective treatments for people in considerable distress so long as the treatments are reasonably safe.

Moreover, it was already known that antidepressants and analgesics had failed to help a number of patients. Accordingly all the patients considered had further combinations of drugs.

The most successful single type appeared to be the phenothiazines since all the twelve best results occurred with them. Ten of the twelve best results were also associated with antidepressants. Antihistamines were associated with five of the best results, but the antihistamines used on their own for a few days initially seemed ineffective. Antihistamines were valuable, however, for reasons to be mentioned, in supplementing night sedation.

The usual dosages of antidepressants were employed. That of the favourite phenothiazine (pericyazine), was from as little as $5.0 \mathrm{mg}$ daily to as much as $225.0 \mathrm{mg}$ daily, the higher dose ranges only being approached gradually.

The pattern of treatment which evolved was largely as follows:

A patient, often already taking an antidepressant would be given promethazine at night, and the dose 
of the antidepressant increased if feasible to assist sleep. Nitrazepam might also be used to promote sleep if required. After 3 or $\mathbf{4}$ days there was usually little improvement and pericyazine would be introduced once or twice a day with a larger dose at night, gradually increasing until good sleep obtained and the patient tended to complain of a dry mouth and drowsiness by day as well (pericyazine is a relatively sedative phenothiazine). After two or three restful nights the patients generally appeared better and said their pain was improved, in some instances dramatically so. But reduction of the day-time dose of pericyazine without a relapse of insomnia ordinarily caused an exacerbation of the pain. A valuable and distinct effect was also obtained by more vigorous use of the non-narcotic drugs in addition. Thus, a patient taking say, two Distalgesic tablets three times a day and waiting for them until his pain was quite severe would be given two or three such tablets, five times daily, punctually at fixed times such that the preceding doses had not had time to wear off. There is an impression (Vitali, 1971; Foster, 1971; Winner, 1971) which we share that it is very important once pain has been reduced or abated to prevent its resurgence in this way. If it is allowed to return in full force it takes more than just one or two doses again to restore the benefit that has been lost.

The good effects of any of these combinations of drugs may also be lost by the administration of barbiturates or of alcohol. The same applies to narcotic drugs. The first two and perhaps also the third reduce the potency of other medication by virtue of their tendency to induce hepatic enzymes. In this connection promethazine is useful with nitrazepam for its effect as a mild hypnotic, supplementing the night-time doses of antidepressants and phenothiazines. The following case histories illustrate the effect of the psychotropic drugs.

\section{Case 1}

A married 50-year-old woman who presented in May 1971 with continuous severe right facial pain of over 3 year's duration. In January 1968 two upper premolar teeth were extracted for toothache and the gums were stitched because of a tendency to bleed. A month later she developed pain in the gums at the site of extraction, not relieved by the subsequent removal of the adjoining canine tooth. Over a period of about 6 months the pain became more intense and spread so that for over $2 \frac{1}{2}$ years she had continual deep aching pain affecting a triangle of the right side of the face in an area marked out by the upper lip and gum, the nose, the orbit, the temporo-mandibular joint and the tragus of the ear. There was also a tingling numbness 'like an exposed nerve' and she was gentle in washing the area and would not allow her children to kiss it. She continued at work taking some 150 paracetamol or Distalgesic tablets a week but was depressed and had frequent suicidal thoughts. No physical abnormality was detectable by physical examination or by investigations including blood count, CSF examination, EEG, brain scan or right carotid and vertebral angiograms. Nevertheless, the condition was thought to have an organic basis and her depression to be secondary to the pain. Substantial and increasing relief appeared within 5 days with the use of amitriptyline $75 \mathrm{mg}$ nocte, pericyazine $10 \mathrm{mg}$ t.d.s., $20 \mathrm{mg}$ nocte, and 16 Distalgesic tablets daily. The pain was only present then, on waking, for about an hour until her first medication in the day began to take effect. Six weeks later she had reduced her total dose of pericyazine to $25 \mathrm{mg}$ nocte because the day-time dose made her too relaxed. She continued to use amitriptyline $75 \mathrm{mg}$ nocte and if pain seemed to be about to recur it was prevented by taking two Distalgesic tablets at a time. There were feelings of discomfort but no actual pain.

\section{Comment}

Both amitriptyline and pericyazine were important first of all in securing good sleep. They appeared to reduce the overall level of pain so much that became possible to abolish it with only small doses of previously insufficient analgesics. In patients with pain due solely to depression, analgesics are usually not necessary as a supplement to antidepressants. In addition the effect of amitriptyline and pericyazine was so quick to appear that it is unlikely to have been related principally to an antidepressant effect. It is more likely to have been due to an analgesic effect of pericyazine, and perhaps a dual antidepressant and analgesic effect of amitriptyline.

\section{Case 2}

Case 2 is a married professional woman born in 1924, the bread-winner of her family with a much older invalid husband, and two sons aged 14 and 8 years, handicapped by congenital illness and in receipt of private education. Her childhood was unhappy and she was nervous and shook easily but served in the WAAF, was a sergeant during the war and was mentioned in despatches. Her marriage was happy. In July 1964 she sustained a partial right median nerve lesion which produced causalgia which persisted despite settlement of a legal claim in March 1970. Combined antidepressants in the form of trimiprazine at night, and phenalzine by day and chlordiazepoxide produced only temporary improvement. She was first seen by us in December 1970 when she had severe pain, sometimes extending to the elbow and shoulder. She said it wore her out and she would have committed suicide were it not 
for her children. She held her right hand slightly adducted and was tense and tearful. At the time of referral she was having trimipramine $150 \mathrm{mg}$ nocte, phenelzine $15 \mathrm{mg}$ t.d.s. and chlordiazepoxide $10 \mathrm{mg}$ t.d.s. She was asked to continue these drugs adding promethazine $25.0 \mathrm{mg}$ nocte. No improvement having occurred after 1 week she was then told to add pericyazine $5 \mathrm{mg}$ mid-day and $10 \mathrm{mg}$ nocte rising to $10 \mathrm{mg}$ mid-day and $20 \mathrm{mg}$ nocte. A further increase of pericyazine to $25 \mathrm{mg}$ b.d., $50 \mathrm{mg}$ nocte abolished her pain altogether within 3 weeks of starting treatment.

She remained well for 2 weeks when oedema of the legs developed, a complication sometimes noted with combined antidepressants and a phenothiazine, and she was advised to reduce the pericyazine, which she did, whereupon pain recurred. She was therefore asked to stop the phenelzine and restore the pericyazine. Within 2 days the pain was again abolished and after 10 days the oedema resolved.

Some drowsiness was noted with the pericyazine but she was able to continue with all her responsibilities and remained free of pain.

In February 1971 a programme was arranged to reduce drugs which might not be required and she dispensed successfully with promethazine and chlordiazepoxide. The pericyazine was also reduced to $87.5 \mathrm{mg}$ daily. Then her trimipramine was also gradually reduced to $50 \mathrm{mg}$ nocte.

In May 1971 she returned for an urgent consultation because of severe depression which had developed insidiously as her drugs were reduced. There was no pain but she was unable to cope with her work and she spent her time sitting around, lacking energy. She was deluded that it was impossible to help her, that she had spent extravagantly, that she could not afford the rail fare for her NHS appointments, and that she would not recover. Physically she had a mask-like facies, cogwheel rigidity in the limbs combined with akathisia and involuntary movements of the tongue at rest. Conjugate deviation on upward gaze was lost.

She was thought to have a drug-induced syndrome of parkinsonism and endogenous depression. She would only agree to reduce her pericyazine (whereupon her pain recurred in part) and not to stop it. The restoration of trimipramine $150 \mathrm{mg}$ nocte and the use of orphenadrine $50 \mathrm{mg}$ t.d.s. resolved her depression and parkinsonism within 3 weeks (i.e. by June 1971) and she has remained well since that time, taking $150 \mathrm{mg}$ of trimipramine, $150 \mathrm{mg}$ of orphenadrine and $100 \mathrm{mg}$ of pericyazine, daily, the latter two drugs in divided doses.

\section{Comment}

In this case repeated reductions of pericyazine were accompanied by a return of pain, and the relief of causalgia was dose-dependent. The complications sustained indicate a potential use for tricyclic drugs and sometimes anti-parkinsonian ones in order to permit the continued employment of pericyazine in a relatively high dose.

The analgesic effect of pericyazine was apparently specific in this patient.

\section{Side-effects and precautions}

This last case leads on to a consideration of the side-effects from these not inconsiderable doses of drugs. Those of the antidepressants are well-known and will not be reviewed. It is becoming increasingly recognized that phenothiazines may cause depression and parkinsonism simultaneously, the most notable evidence probably being that of de Alarcon \& Carney (1969). Our second patient described illustrates how a reversible syndrome of parkinsonism and depression emerged when the antidepressants were stopped and pericyazine continued. It seems not unlikely that both these consequences were initially averted by her antidepressants. In this connection the spontaneous occurrence of parkinsonism and depression together and their apparent response to antidepressants and sometimes ECT is apposite. In the treatment of pain by phenothiazines it is therefore probably wise to use antidepressants.

A troublesome side-effect which might be anticipated with these combinations is postural hypotension but we have not had complaints of it in this series.

Transient impairment of micturition is a problem sometimes making necessary reduction of the antidepressant. Constipation almost always occurs and is usually manageable but we have had a patient (not in this series) who became so constipated that his haemorrhoids prolapsed and he required a haemorrhoidectomy. The production of oedema is also not confined to phenelzine or iproniazid. Tricyclic antidepressants and phenothiazines seem to provoke water-retention at times and especially when in combination, although the patient described is the only one in this series who developed frank oedema.

It is worth remarking further that some patients, having gained control of their pain-or thinking that the drugs do not help, attempt to stop their medication suddenly. In our experience their pain is usually severe after this and they then recognize the help the medication was giving. But some deliberately cut their dose, knowing their pain will be worse, because their maximum benefit is accompanied by too much drowsiness and they feel the need to be able to concentrate better at work.

\section{Discussion}

We hope this account has shown that a combina- 
tion of psychotropic drugs, especially antidepressants and phenothiazines, but possibly also antihistamines, can be very useful in the control of chronic pain. It is evident that the combination is not a panacea and that it can also cause troublesome side-effects. Apart from its therapeutic use the most interesting question it raises is the relationship to the experience of pain. Although tranquillity plays a substantial part in curing pain the results described suggest to us that the phenothiazines, antidepressants and antihistamines may have an analgesic action which is in part independent of their mood-altering effects. It is reasonable to suppose that this action is on the multi-synaptic small-cell system, as it is called by Noordenbos (1959). In other words the effect is probably on the reticular activating system and on related cell systems which are relatively slow-conducting. This is not to deny the intimate relationship between pain and mood, but rather to suggest that they are affected by closely-related neuronal systems which, although not identical, can each respond to the same types of pharmacological agent.

\section{Acknowledgment}

H.M. wishes to thank the Chartered Society of Queen Square for support.

\section{References}

DE Alarcon, R. \& Carney, W.M.P. (1969) Severe depressive mood change following slow-release intramuscular fluphenazine injection. British Medical Journal, 3, 564.

Bradley, W.H. (1971) (Ed.) Proceedings of a Symposium on Pain in Disablement. National Fund for Research into Crippling Diseases, London.

Bloomfield, S., Simard-Savoie, S., Bernier, J. \& TetREAULT, L. (1964) Comparative analgesic activity of levomepromazine and morphine in patients with chronic pain. Canadian Medical Association Journal, 90, 1156.

Cassinari, V. \& Pagni, C.A. (1969) Central Pain: A Neurosurgical Survey. Harvard University Press, Cambridge, Mass.

Chavanne, J. (1960) Treatment of pain with a group of phenothiazine amines. Presse Médicale, 68, 2347.

Egbert, L.D., Battit, S.E., Welch, C.E. \& Bartlett, M.K. (1964) Reduction of post-operative pain by encouragement and instruction of patients: A study of doctor-patient rapport. New England Journal of Medicine, 270, 825.
Foster, C.A. (1971) In: Proceedings of a Symposium on Pain in Disablement, p. 34. National Fund for Research into Crippling Diseases, London.

HoLT, N.F. (1964) Treatment of chronic tension headache. Lancet, ii, 1067.

Lance, J.W. \& Curran, D.A. (1964) Treatment of chronic tension headache. Lancet, ii, 1236.

Lasagna, L. \& De Kornfeld, T.J. (1961) Methotrimeprazine: A new phenothiazine derivative with analgesic properties. Journal of the American Medical Association, 178, 887.

LASCELles, R.G. (1966) Atypical facial pain and depression. British Journal of Psychiatry, 112, 651.

Lassman, P.L., Moody, J.F. \& GryspeerdT, G.L. (1959) Central pain due to cerebral ischaemia. Folia psychiatrica, neurologica et neurochirurgica Neerlandica, 62, 34.

MERSKEY, H. (1965) The characteristics of persistent pain in psychiatric illness. Journal of Psychological Research, 9 291.

Merskey, H. \& Spear, F.G. (1967) Pain: Psychological and $\frac{\vec{\infty}}{\infty}$ Psychiatric Aspects. Baillière Tindall and Cassell; London. if

Montilla, E., Frederik, W.S. \& Cass, L.J. (1963) Anal- ס gesic effect of methotrimeprazine and morphine: $A \stackrel{\square}{\circ}$ clinical comparison. Archives of Internal Medicine, 111, 725.

Noordenbos, W. (1959) Pain. Elsevier, London.

Panaccio, V. (1959) Trimeprazine: A new phenothiazine derivative for treatment of pruritic dermatoses. Canadian Medical Association Journal, 80, 885.

Paradis, B. (1962) Analgesic and anaesthetic properties of levomepromazine (Nozinan) (7044R.P.). Canadian Anaesthetists Society Journal, 9, 153.

ROSNER, S. (1957) The potentiating effect of diphenhydraming $\overrightarrow{0}$ hydrochloride (Benadryl). Journal of Nervous and Mento $N$ Disease, 125, 229.

SAUNDERS, C. (1963) The treatment of intractable pain in terminal cancer. Proceedings of the Royal Society of Medicine, 56, 195.

SAunders, C. \& WinNer, A. (1971) Analgesics in terminal disease. British Medical Journal, 3, 245.

Sigwald, J., Boutrier, D. \& Caille, F. (1959) The treatment of herpes and post-herpetic pain. Study of the results obtained with levomepromazine. Therapie, 14, 818 .

Sigwald, J. HeberT, H. \& Quetin, A. (1957) The treatment of herpes and post-herpetic pain (and other resistant forms of pain) with phenothiazine derivatives. Semaine des hôpitaux de Paris, 33, 1137.

Vitali, A. (1971) In: Proceedings of a Symposium on Pain in Disablement, pp. 32-3. National Fund for Research in Crippling Diseases, London.

Winner, A. (1971) In: Proceedings of a Symposium on Pain in Disablement. National Fund for Research in Crippling Diseases, London. 